\title{
Rainfall-Runoff Modelling using HEC-HMS Model for Shipra River Basin in Madhya Pradesh, India
}

\author{
Salil Sahu $^{1 *}$, S. K. Pyasi ${ }^{1}$, R. V. Galkate ${ }^{2}$ and R. N. Shrivastava ${ }^{1}$ \\ ${ }^{1}$ Jawaharlal Nehru Krishi Vishwa Vidyalaya, Jabalpur, India \\ ${ }^{2}$ National Institute of Hydrology Regional Centre, Bhopal, India \\ *Corresponding author
}

\section{Ke y w o r d s \\ HEC-HMS Model, Shipra River Basin, Rainfall-Runoff}

\section{Article Info}

Accepted:

26 July 2020

Available Online:

10 August 2020

\section{A B S T R A C T}

In this study, HEC-HMS hydrological model version 4.2.1 was used to simulate the Rainfall-Runoff process in the Shipra basin at Ujjain G/d site, located in the Madhya Pradesh state of India. The basin model of HEC-HMS was created using HEC-GeoHMS and Arc-Hydro Tool in ArcGIS. The rainfall losses were estimated by the widely known Soil Conservation Service - Curve Number model, while the Soil Conservation service Unit Hydrograph model was used to transform excess rainfall into a direct rainfall hydrograph. The Routing of the total runoff from the outlet of the sub-basin to the outlet of the whole basin was achieved by using the Lag model. To estimate the reference evapotranspiration, FAO Penman-Monteith method was used in CROPWAT 8.0. The calibration of the model was performed using the rainfall data of Indore, Dewas, and Ujjain gauging station and discharge data of Ujjain gauging discharge station, from 2000 to 2003. Similarly, Validation was performed for the period from 2004 to 2006 on the daily time step. The model performance was evaluated based on the computed statistical parameters and visual examination of the hydrograph. For the Calibration period of the continuous modeling, the performance of the model was very good, with Coefficient of Determination $\left(\mathrm{R}^{2}\right)=0.85$, Nash-Sutcliffe Efficiency $(\mathrm{NSE})=0.72$, Root Mean Square Error (RMSE) was $14.4\left(\mathrm{~m}^{\mathrm{m}} / \mathrm{s}\right)$, and Mean Absolute Error was $53.9(\mathrm{~m} 3 / \mathrm{s})$. similarly, the model performance for the validation was good, with $\mathrm{R}^{2}=0.88, \mathrm{NSE}=69, \mathrm{RMSE}=13.9$ $\left({ }^{\mathrm{m} 3} / \mathrm{s}\right)$ and Mean Absolute Error $=63.9\left(\mathrm{~m}^{\mathrm{m}} / \mathrm{s}\right)$. The results of the calibration and validation values were very satisfactory. Finally, it can be concluded that the model can be used with reasonable approximation in hydrological simulation in the Shipra basin.

\section{Introduction}

Construction and application of watershed models that describe precipitation to stream flow Processes have been a prime focus of hydrological research and investigations for numerous decades (Jackeman and
Hornberger, 1993). The runoff computation from ungauged or poorly gauged catchment is a serious challenge in developing countries like India where higher operation and maintenance costs differed gauging on small and medium rivers (Jaiswal et al., 2020). The knowledge-based or data-driven hydrological 
models were developed and used by researchers to extend rainfall records and address modeling issues (Kar et al., 2015, 2017). Many watershed models have been developed based on the conceptual representation of the physical water flow process over the entire basin area to model the rainfall processes (Madsen 2000). The Hydrologic Engineering Centre -Hydrological Model System (HEC-HMS) is one such model that supports both lumped parameter based modeling and distributed parameterbased modeling (Agarwal, 2005). HEC-HMS provides a suite of hydrological modeling options, with the main components focusing on determining runoff hydrographs from subbasins and routing the hydrographs through the channels to the study outlets (Beighley et al., 2003). HEC-HMS is a hydrologic model which is developed by U.S. Army Corps of Engineers, Hydrologic Engineering Centre (HEC) can predict runoff in response to precipitation of dendritic watershed. The HEC-HMS uses the separate model to represent various components of the rainfallrunoff process like the Loss model for calculating precipitation losses, Transform model for transforming excess precipitation into the direct surface runoff, Base flow model for base flow estimation, and Routing model for routing the reach. The model combines a Basin model, Meteorological model, Control specification, and Time series data with the run option to obtain the model result. The basin model is the physical representation of the basin. The rainfall and evapotranspiration data needed for simulating the watershed process are stored in the meteorological model, control specification controls the period for which the model is to be run and time-series data component, which is used for data input (i.e precipitationdischarge data). The loss model is also called the runoff volume model as it calculates precipitation losses depth, which is subtracted from the Mean Areal Precipitation (MAP) depth to get excess precipitation, as this depth is considered to be uniformly distributed over the whole basin, so it represents a volume of runoff.

Derdour et al., (2018) simulated runoff in the semi-arid region in Ain Sefra watershed Ksour mountains (SW Algeria) using HECHMS hydrological model, used SCS curve number to calculate loss rate and SCS unit hydrograph model to simulate the runoff rate. After calibration and validation, the simulated peak discharge was very close to the observed value. Haibo et al., (2018) used the HECHMS model for forecasting flood in Huan river basin of Henan, China, ArcGIS was used to extract watershed information according to river DEM data. The net rainfall was calculated through the initial constant rate loss model and the surface runoff was calculated using the Snyder unit line model. Muskingum method was used for routing. The calibrated and verified using historical observed data. The result showed the acceptable range of determination and coefficient of the agreement. Vishweshwaran et al., (2017) used the HEC-HMS model for event-based rainfall-runoff modeling for krishna basin using daily rainfall Runoff data. SCS-CN method was used for loss estimation and SCS unit hydrograph for transforming excess precipitation into a direct runoff hydrograph. the model was calibrated for the monsoon period of 2011 and validated for the 2007 and 2013 monsoon period. Rathod et al., (2015) developed a lumped continuous hydrological model for estimating runoff for different rainfall events in three sub-basins of the Tapi river used the Green-ampt method as a loss method and compared the SCS unit hydrograph and Snyder unit hydrograph method as a transform method and found that the SCS unit hydrograph method gives better results. Halwatura et al., (2013) made an attempt to set a Rainfall-Runoff model for Attangalu Oya river basin Sri Lanka using 
HEC-HMS model, he compared different transform and loss method and found that the combination of Snyder unit hydrograph method as a Transform method and the deficit and constant method as a loss method give more reliable results for Attangalu Oya river basin

In the present study, the HEC-HMS model was used to model the Rainfall-Runoff process in the Shipra basin at the Ujjain G/d site. In the study, the SCS Curve Number model has been used as a loss model, SCS unit hydrograph as a transform model, and Lag modal as a routing model.

\section{Study area}

The Shipra, also known as the Kshipra, emerges from the Kakribardi hills in Vindhya Range north of Dhar and flows north across the Malwa Plateau to join the Chambal River. It is one of the religiously important rivers for Hindu. The holy city of Ujjain is situated on its right bank Shipra river has huge importance as far as the religious values are concerned. Shipra river basin has been extended between, $76^{\circ} 06^{\prime} 20^{\prime \prime}$ and $75^{\circ} 55^{\prime} 60^{\prime \prime}$ North Latitude and $22^{\circ} 97^{\prime} 00^{\prime \prime}$ and $23^{\circ} 76^{\prime} 20^{\prime \prime}$ East Longitude and covers an area of 5679 sq. $\mathrm{km}$. The river travels a total course of about $190 \mathrm{~km}$ through four districts namely, Indore, Ujjain, Dewas, and Ratlam before joining Chambal River near Kalu-Kher village. Most of the Shipra basin area falls in Indore and Ujjain districts however small parts come under Ratlam and Dewas districts (Fig. 1).

Over the years the river has lost its naturality and now runs dry for a period of about 5 to 6 months in a year. The water of the Shipra is utilized for drinking, industrial use, and lift irrigation purposes. It is reported that there is a general practice of pumping water from the river for providing irrigation to surrounding agricultural fields. The average annual rainfall of the study area is about $931.87 \mathrm{~mm}$. The topography is normally rolling to undulating. Due to undulating topography, the upland areas have excessive surface runoff which results in soil erosion. The soil removed from upland areas gets accumulated on the valley land, which has moderate to poor drainage.

\section{Data collection}

The daily rainfall data of Indore, Ujjain, Dewas rain gauge stations from 20002006was used in the study. The observed discharge data of the Ujjain gauging discharge site was used for the calibration and validation of the model. The meteorological data of Indore observatory like relative humidity, wind speed, sunshine hours, mean and maximum temperature, etc. were used for estimation of evapotranspiration. SRTM DEM of $30 \mathrm{~m}$ resolution of the study area which was downloaded from www.earthtexplorer.usgs.gov. LULC map of Madhya Pradesh which was downloaded from www.bhuvan.nrsc.gov.in. Soil map of Madhya Pradesh which was also used in the study.

\section{Development of the HEC-HMS model}

\section{Development of basin model for HEC- HMS}

In the process of model development, the development of the basic model is the first step. Which can be developed either by manual input of hydrologic elements and connecting them in a dendritic network or by using HEC-GeoHMS with DEM in Arc-Gis. In the present study, HEC-GeoHMS and ArcHydro tool was used in ArcGIS for developing basin model. In this, the study area watershed was delineated and divided into three sub-basins (Indore, Ujjain, Dewas). The basin model imported in HEC-HMS is shown in fig. 2 . 
Selection of modelling methods and estimation of model parameters

Loss Model: It is used for estimating excess precipitation, by deducting the total losses from the total precipitation. In the present study Soil Conservation Service (SCS) Curve Number method was used for loss estimation.

\section{Estimation of the SCS-CN method} parameter

SCS Curve Number method in HEC-HMS requires the estimation of curve number, percent of impervious, and initial abstraction as input data for each sub-basin. The following procedure was followed for the estimation of input parameters: -

\section{Curve Number}

The Curve Number is the function of soil type, land use/land cover, and antecedent moisture condition. For this purpose, the LU/LC Map of the study area was downloaded from www.bhuvan.nrsc.gov.in and was classified based on the available features in the study area. Similarly, the Soil Map of the study area was digitised and was provided with different soil hydrological groups. Based on the soil group, LU/LC class and antecedent moisture condition the Composite Curve Number was calculated for each sub-basins of the study area. The LU/LC and Soil Map of study area are shown in Fig.3 $\& 4$ respectively.

\section{Initial Abstraction}

It represents the percent of the vegetation, which prevents permanently or temporarily the precipitation from reaching the soil surface. This value was estimated as the function of the curve number using the below equation, which is shown in Table.
$I_{\alpha}=0.2 *\left(\frac{25400-254 * C N}{C N}\right)$

\section{Percent impervious}

Percent of impervious represent the percent of basin surface which is impervious and directly connected to the stream flow. In our case, and due to the difficulty to determine precisely its value, it was related to the percent of built-up. So, the percent of built-up in each sub-basin was taken as percent impervious, as the built-up has minimum infiltration.

\section{Transform model}

It is also called the Direct Runoff model as it transforms excess precipitation into direct runoff hydrograph. In the present study Soil Conservation Service (SCS) Unit Hydrograph model was used.

\section{Estimation of SCS-unit hydrograph model parameter}

The SCS unit hydrograph method requires the estimation of lag time as the only input data for each sub-basin. The following procedure was followed for the estimation of lag time for each sub-basin: -

\section{Lag time}

Lag time is the time lag between peak rainfall amount and the peak runoff. Lag time for each sub-basin was calculated in the relation of time of concentration, which is estimated using the KIRPICH equation. Slope and longest flow path of each sub-basin was calculated using HEC-GeoHMS tool in ArcGis.

$$
\mathrm{T}_{\text {lag }}=0.6^{\mathrm{T}_{\mathrm{c}}}
$$


Where,

$\mathrm{T}_{\text {lage }}$ lag time (min)

$\mathrm{T}_{c}=$ Time of concentration $(\mathrm{min})$

$L=$ Maximum length of travel of water or

longest length of travel of water $(\mathrm{m})$

$\mathrm{S}=$ Slope of the catchment

\section{Routing model}

Flood routing is the technique of determining the flood hydrograph at the downstream of the river by utilizing the inflow data of upstream. The Routing of the total runoff from the outlet of the sub-basins (Indore and Dewas) to the outlet of the whole basin was achieved by using Lag model

\section{Lag Model}

This is the simplest of the included routing models. With it, the outflow hydrograph is simply the inflow hydrograph, but with all ordinates translated (lagged in time) by specified duration. The flows are not attenuated, so the shape is not changed. This model is widely used, especially in urban drainage channels (USACE-HEC, 2006).

\section{Estimation of lag model parameter}

The lag routing model was used as a routing method in HEC-HMS. it only requires the estimation of time, the lag between the inflow and the outflow hydrograph, this was estimated using the following procedure -

\section{Lag}

The assumption made for the reach was constant flow depth over the total travel time. the lag model only requires the only estimation of lag routing time in minutes for the channel. lag time was calculated by using the below equation -
$T_{t}=\frac{L}{60 V}$

$V=K S^{0.5}$

Where,

$L=$ length of reach

$V=$ velocity

$K=$ function of land cover with the effect measure by the value manning's and the hydrologic radius, the river bed was assumed to be composed mainly of sand and gravel, therefore the value of $\mathrm{K}$ was taken as 5 (Ward and Trimble, 2004, pp.138). $S=$ Slope

\section{Estimation of evapotranspiration}

HEC-HMS require monthly average Potential Evapotranspiration data, that was estimated using the Penman-Monteith equation in CROPWAT Model, but it also requires crop coefficient for the conversion of Potential Evapotranspiration into Actual Evapotranspiration, As Trivedi et.al., (2018) worked on Rainfall-Runoff modeling using RRL AWBM model for Shipra basin and estimated average crop coefficient for every month based on the crop grown in the region, so monthly value of crop coefficient was taken from it.

\section{Model calibration and validation}

Before a hydrological model can be considered to have reliable output, it needs to be Calibrated \& Validated using the observed discharged data. The calibration is the process of optimizing the model parameters to get the good goodness of fit between the simulated and observed hydrograph. In the present study, model calibration was done by using the estimated parameters to achieve a good fit between simulated and observed data. The auto-calibration (through optimization trials) available in the HEC-HMS model was used for optimizing the model parameters. Two- 
third of the available rainfall-discharge data i.e. from 2000-2003 was used for calibration and in the presence of these data, Optimization of the parameters was done, using a systematic search procedure that yields the best fit between the observed and computed runoff. In HEC-HMS, from the two different search algorithms (Nelder and Mead search algorithms and Univariate Gradient search algorithm) the Univariate Gradient search algorithm was selected for the study. A variety of objective functions are provided in HEC-HMS to measure the goodness of the fit between the simulated and observed runoff in different ways such as peak weighted RMS error, percent error peak, percent error volume, sum absolute residuals, sum squared residuals, and time-weighted error (USACEHEC,2006). These objective functions were recognized one by one and the objective function that gives the better result, indicates the end of calibration.

Table.1 Estimated and Calibrated Model parameter

\begin{tabular}{|c|c|c|c|c|c|c|}
\hline \multirow{2}{*}{$\begin{array}{c}\text { Model } \\
\text { parameters }\end{array}$} & \multicolumn{2}{|c|}{ Dewas } & \multicolumn{2}{c|}{ Ujjain } & \multicolumn{2}{c|}{ Indore } \\
\cline { 2 - 7 } & $\begin{array}{c}\text { Estimated } \\
\text { Value }\end{array}$ & $\begin{array}{c}\text { Calibrate } \\
\text { d Value }\end{array}$ & $\begin{array}{c}\text { Estimated } \\
\text { Value }\end{array}$ & $\begin{array}{c}\text { Calibrated } \\
\text { Value }\end{array}$ & $\begin{array}{c}\text { Estimated } \\
\text { Value }\end{array}$ & $\begin{array}{c}\text { Calibrated } \\
\text { Value }\end{array}$ \\
\hline Curve Number & 76 & 81.88 & 76 & 69.98 & 77 & 67.67 \\
\hline $\begin{array}{c}\text { Initial } \\
\text { Abstraction (mm) }\end{array}$ & 16 & 11.81 & 15 & 9.6 & 14 & 9.46 \\
\hline Lag Time (min) & 1277.26 & 1296.0 & 1087.50 & 1103.5 & 753 & 764.27 \\
\hline Lag (min) & & & & & 1668 & 1692 \\
\hline
\end{tabular}

Table.2 Values of Evaluation parameters during calibration

\begin{tabular}{|l|l|}
\hline Measure & Values \\
\hline Coefficient of determination $\left(\mathbf{R}^{\mathbf{2}}\right)$ & 0.85 \\
\hline Nash-sutcliffe efficiency $(\mathbf{N S E})$ & 0.725 \\
\hline Root mean square error $(\mathbf{R M S E})$ & $53.9\left({ }^{\mathrm{m} 3} / \mathrm{s}\right)$ \\
\hline Mean absolute error $(\boldsymbol{M A E})$ & $14.4\left({ }^{\mathrm{m} 3} / \mathrm{s}\right)$ \\
\hline
\end{tabular}

Table.3 Observed and Simulated peak flow and discharge volume during calibration

\begin{tabular}{|l|l|l|l|}
\hline & Simulated & Observed & Difference \\
\hline Volume (MM) & 2257.78 & 1863.52 & 394.25 \\
\hline Peak Flow (M3/S) & 1270.2 & 955.0 & 315.2 \\
\hline Time of Peak & 28Jul2003, 08:30 & 29Jul2003, 08:30 & \\
\hline
\end{tabular}

Table.4 Values of Evaluation parameters during Validation

\begin{tabular}{|l|l|}
\hline Measure & Values \\
\hline Coefficient of determination $\left(\mathbf{R}^{\mathbf{2}}\right)$ & 0.88 \\
\hline Nash-sutcliffe efficiency $(\mathbf{N S E})$ & 0.69 \\
\hline Root mean square error $(\mathbf{R M S E})$ & $63.9\left({ }^{\mathrm{m} 3} / \mathrm{s}\right)$ \\
\hline Mean absolute error $(\boldsymbol{M A E})$ & $13.9\left({ }^{\mathrm{m} 3} / \mathrm{s}\right)$ \\
\hline
\end{tabular}


Table.5 Observed and Simulated Peak Flow \& Discharge volume during Validation

\begin{tabular}{|l|c|c|c|}
\hline Measure & Simulated & Observed & Difference \\
\hline Volume (MM) & 1492.97 & 1015.70 & 477.27 \\
\hline Peak Flow (M3/S) & 2445.3 & 1999.0 & 446.3 \\
\hline Time of Peak & 10Aug2006, 08:30 & 10Aug2006, 08:30 & \\
\cline { 1 - 1 } \cline { 4 - 5 } & &
\end{tabular}

Fig.1 Map of Shipra Basin

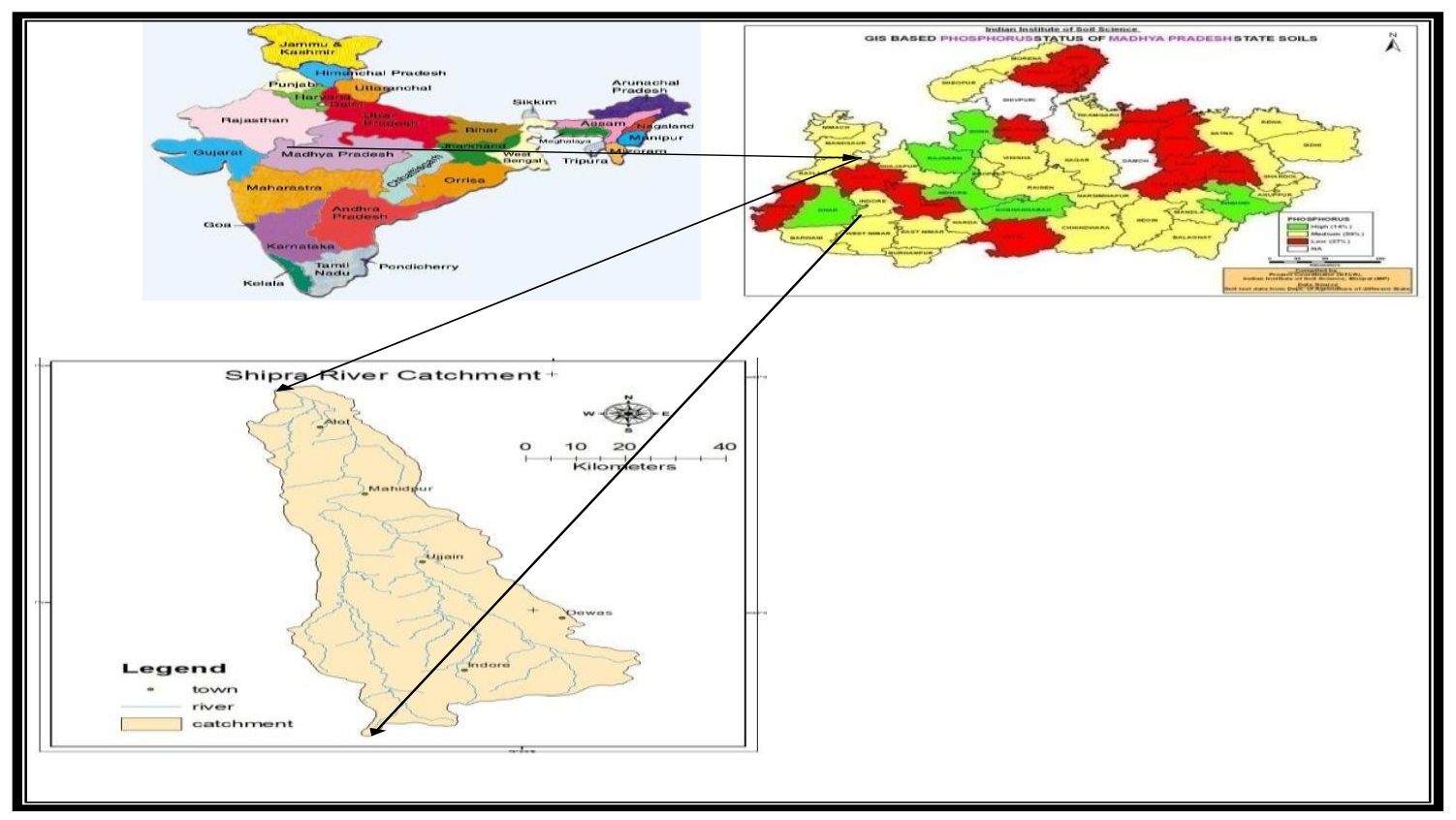

Fig.2 Basin Model of HEC-HMS Model

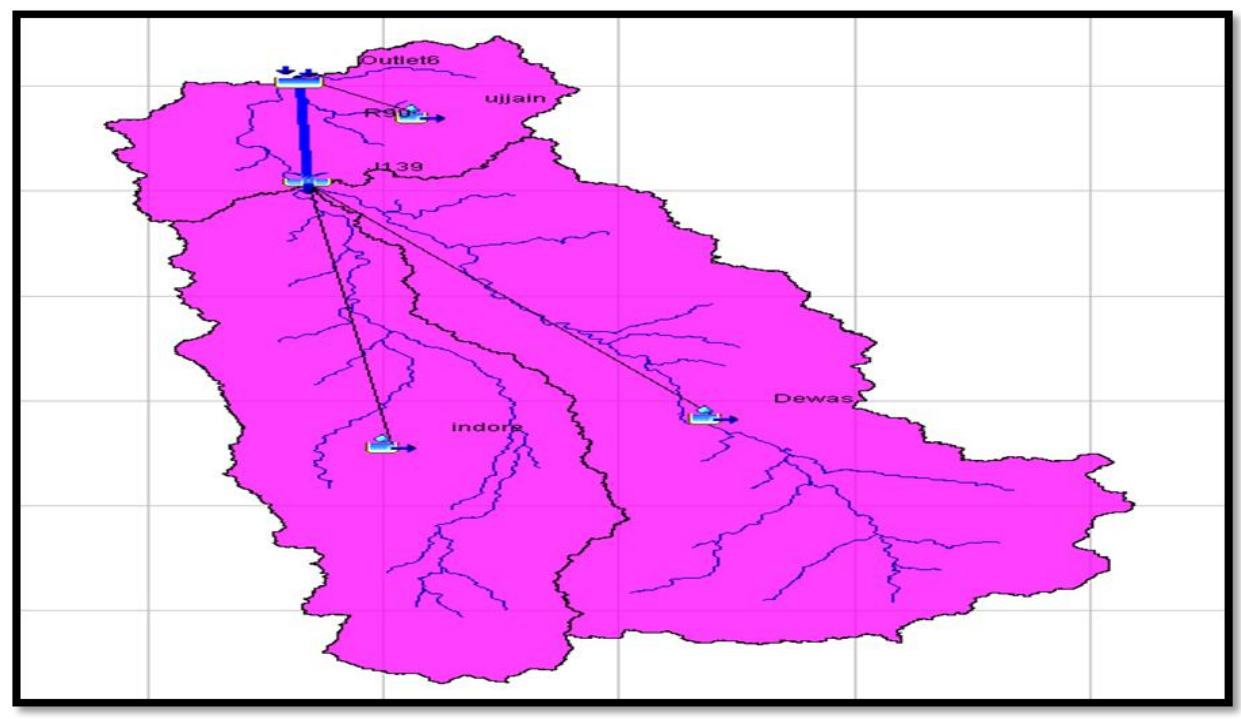


Fig.3 LU/LC Map of Study area

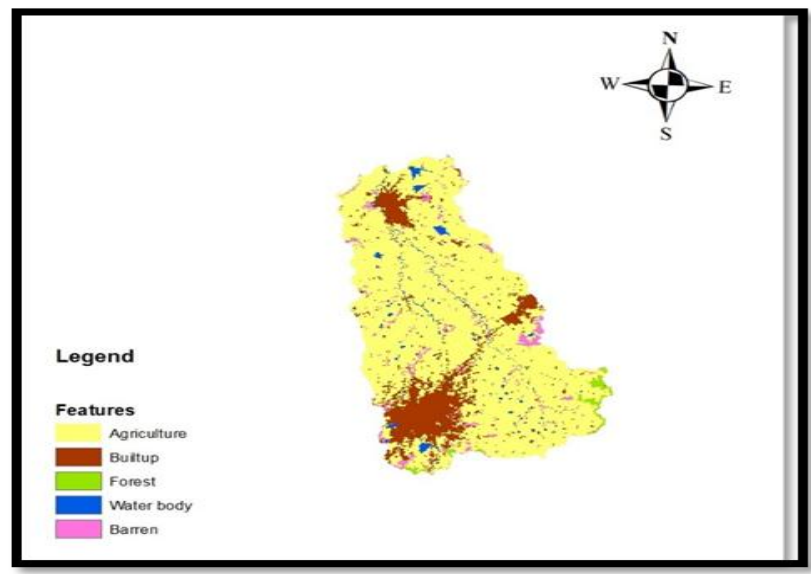

Fig.4 The Soil Map of the study area

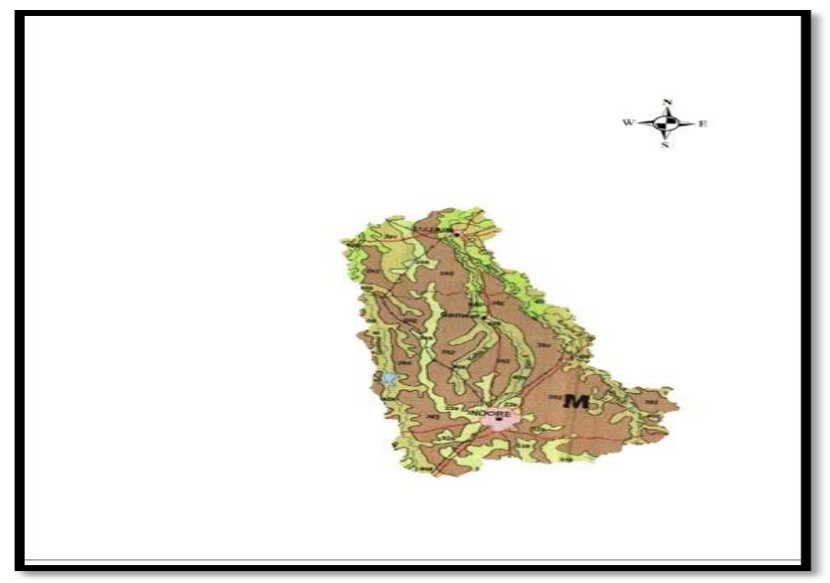

Fig.5 Comparison of Observed \& Simulated Hydrograph obtained during Calibration

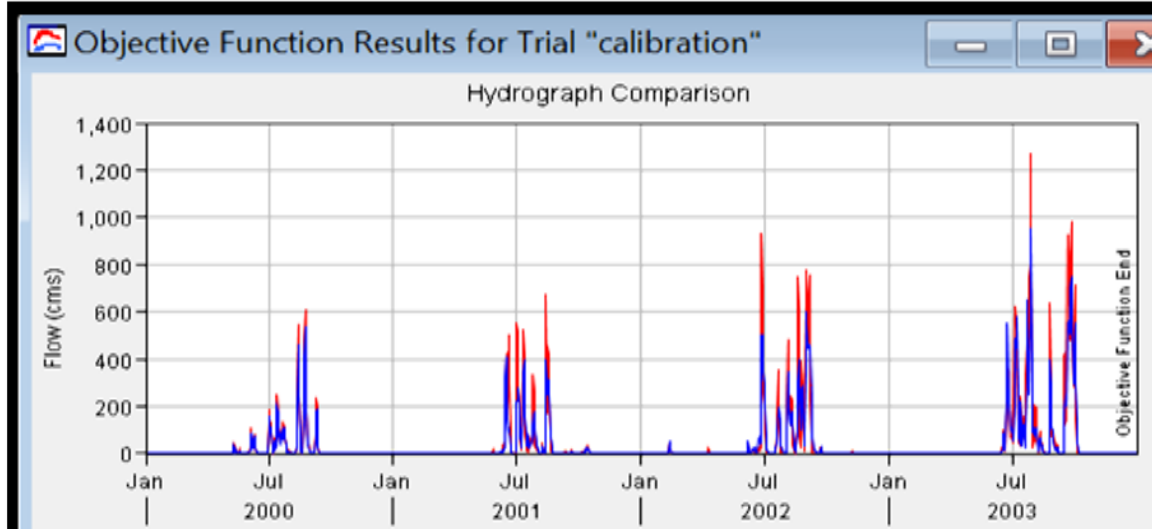

Legend (Compute Time: 22Apr2020, 10:47:49) 
Fig.6 Comparison of Observed \& Simulated Hydrograph during Validation

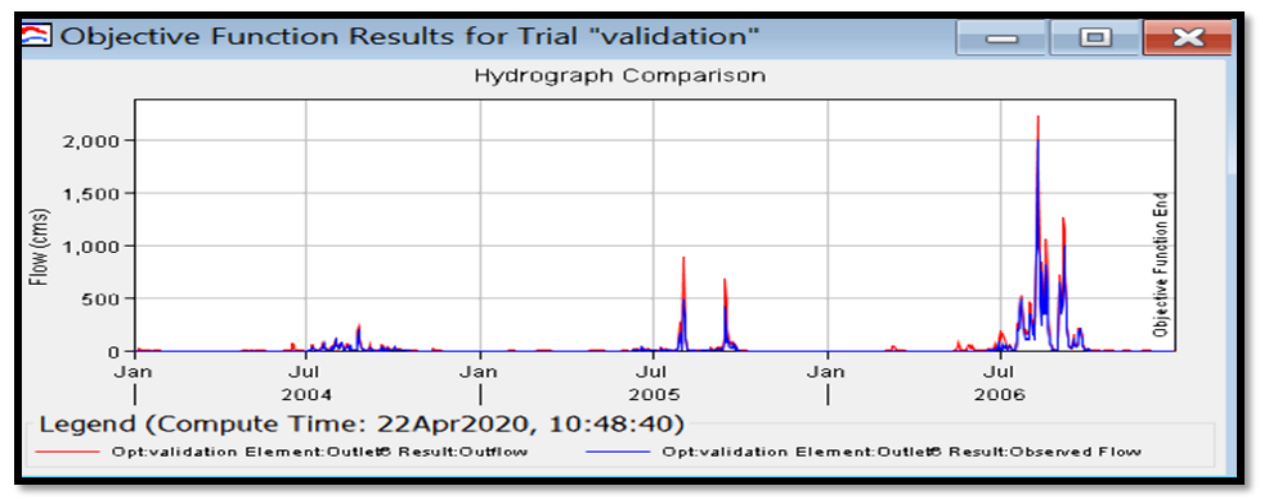

The model validation was done using the optimized parameters found during the calibration. The remaining available one-third of the available discharge data i.e. from 20042006 was used for checking the goodness of fit between observed and simulated runoff.

\section{Results and Discussion}

Basin model is the most important component of HEC-HMS to simulate the rainfall-runoff process over the entire watershed. To develop Shipra river basin model, three subbasins and one routing reach were created using the HECGeoHMSand Arc-Hydrptool in ArcGIS.

The schematic drawing of the basin model of Shipra as shown in Fig.2. The estimated parameter of different methods used in the simulation is shown in Table 1.

\section{Model Calibration}

The optimisation trial tool (auto-calibration) was used for optimizing the model parameter. For this two-third of the observed rainfall discharge data was taken i.e. from 2000-2003. The objective functions were used to compare the simulated and observed hydrograph. The comparison of the simulated and observed hydrograph is shown in fig. 5. In the present study, the objective function of the peak weighted root mean square error was used, as it showed the better value of Nash-SutcliFfe Efficiency, Root Mean Square Error, Mean
Absolute Error, and Coefficient of Determination, that is shown in the table. 2. The observed and simulated peak flow and discharge volume are shown in table 3.

\section{Model Validation}

For validation one-third of the remaining observed rainfall -discharge data was used i.e. 2004-2006. The parameters obtained during calibration was used for validation. The values of Nash-Sutcliffe

Efficiency, Root Mean Square Error, Mean Absolute Error, and Coefficient of Determination, that is shown in table 4. The peaks of the simulated and observed hydrograph show a better fit (Fig. 6). The time to peak and discharge volume was also approximately similar (Table 5).

In conclusion the results based on the Nash Sutcliffe efficiency and the graphical evaluation of the model show that the HEC-HMS is well suited for the simulation of rainfall-runoff in the Shipra river basin. The SCS unit hydrograph method available in the HEC-HMS model to transform excess precipitation into the direct runoff is suitable to model the Shipra river basin. The routing lag model was found to be suitable for routing the reach of the Shipra river. The SCS curve number method used for loss estimation in HEC-HMS model was also successfully applied to Shipra basin. 
The peak flow and the discharge volume obtained during validation was quite similar to the measured values, that shows the applicability of the model for utility and planning of water resource management in the Shiprariver basin.

\section{References}

Beighly, R. E. and Moglen, G. E., (2003), Adjusting measured peak discharges from an urbanizing watershed to reflect a stationary land use signal, Water Resources Research, 39, 4, 1-11.

Derdour, A.et al., (2018). Modelling rainfall runoff relations using HEC-HMS in a semi-arid region: Case study in Ain Sefra watershed, Ksour Mountains (SW Algeria). Journal of Water And Land Development, No. 36 (I-III): 45-55.

Haibo, M. et al., (2018). Application of Synthetic Unit Hydrograph on HEC-HMS Model for flood forecasting. MATEC Web of Conferences 246.

Halwatura, D. et al., (2013). Application of the HEC-HMS model for runoff simulation in a tropical catchment. Environ. Model. Softw.46,155-162. https://doi.org/10.1016/j.envsoft.2013.03.0 06 Agrawal, A. (2005), "A Data Model with Pre and Post Processor for HECHMS", Report of Graduate Studies, Texas A \& M Univ. College Station.

Jaiswal, R. K., et al., (2020). Comparative evaluation of conceptual and physical rainfall-runoff models. Applied Water Science, 10(1),48. https://doi.org/10.1007/s13201-019-11226.

Madsen, H. (2000), "Automatic calibration of a conceptual rainfall-runoff model using multiple objectives." J. Hydrol., 235(3-4), 276-288. Jakeman, A. J., and Hornberger, G. M. (1993). "How much complexity is warranted in a rainfall-runoff model" Water Resource. Res., 29(8). 2637-2649.

Rathod, P.et al.,(2015). Simulation of Rainfall Runoff Process Using HEC-HMS (Case Study: Tapi River, India). Presented at the Hydro 2015 International IIT Roorkee, India, 17-19 December, 2015 20th International Conference on Hydraulics, Water Resources and River Engineering, p.10.

Trivedi, A. et al., (2018). Estimation of Evapotranspiration using CROPWAT 8.0 Model for Shipra River Basin in Madhya Pradesh, India. Int. J. Curr. Microbiol. Appl.Sci.7,11.https://doi.org/10.20546/ijc mas.2018.705.151

Trivedi, A. et al., (2019). Impact of Climate Change Using Trend Analysis of Rainfall, RRL AWBM Toolkit, Synthetic and Arbitrary Scenarios. Current Journal of Applied Science and Technology. 1-18.

USACE-HEC (2000) Hydrologic modeling system HEC-HMS technical reference manual. US Army Corps of Engineers, Hydrologic Engineering Centre (HEC), Davis, USA

USACE-HEC (2006) Hydrologic modeling system HEC-HMS v3.2 user's manual. US Army Corps of Engineers, Hydrologic Engineering Center (HEC), Davis, US

Visweshwaran Ramesh, 2017. Application of the HEC-HMS model for runoff simulation in the Krishnabasin. https://doi.org/10.13140/RG.2.2.13326.054 48

Ward, A.D., n.d. Environmental Hydrology, second. ed. Lewis Publishers.

\section{How to cite this article:}

Salil Sahu, S. K. Pyasi, R. V. Galkate and Shrivastava, R. N. 2020. Rainfall-Runoff Modelling using HEC-HMS Model for Shipra River Basin in Madhya Pradesh, India. Int.J.Curr.Microbiol.App.Sci. 9(08): 3440-3449. doi: https://doi.org/10.20546/ijcmas.2020.908.398 